\title{
Infrared Spectroscopic Investigations of Effect of Strong Resonance Stabilized Intramolecular Hydrogen Bonding in 1-(1-Hydroxy-2-naphthyl)-3-(phenyl or Substituted phenyl)- prop-2-en-1-ones and on their Complexation with Some Transition Metals
}

\author{
ENUSALI R. AGHARIA \\ Department of Chemistry, SVKM's Mithibai College, Vile-Parle (West), \\ Mumbai-400056, India \\ mhea22@rediffmail.com
}

Received 22 October 2014 / Accepted 8 November 2014

\begin{abstract}
Some copper(II), nickel(II) and cobalt(II) complexes of naphthalene analogues of 2'-hydroxychalcones have been synthesized and characterized. The complexes have the general formula $\mathrm{ML}_{2} \cdot \mathrm{XH}_{2} \mathrm{O}(\mathrm{X}=2$ or 0$)$ where, $\mathrm{L}$ is the deprotonated ligand, the naphthyl chalcone and $\mathrm{M}$ is the divalent metal ion. The present paper deals with the effect of strong resonance stabilized intramolecular hydrogen bonding on the IR spectral properties of the naphthalene analogues of 2'hydroxychalcones as mentioned above and also on their complexation with transition metals such as $\mathrm{Cu}(\mathrm{II}), \mathrm{Ni}(\mathrm{II})$ and $\mathrm{Co}(\mathrm{II})$. The conjugated chelation alters considerably the IR spectral properties of these compounds and plays a prominent role in coordination chemistry. IR spectroscopy is the most sensitive and direct method for the study of hydrogen bonding.
\end{abstract}

Keywords: Chalcones, Metal complexes, Intramolecular hydrogen bonding, Conjugated chelation

\section{Introduction}

The chemistry of chalcones and related compounds has been recognized as a significant field of study. Due to synthetic importance and varied biological activities of chalcones, an increasing amount of interest has been taken in their synthesis and various studies. The enone function in the chalcone due to the keto-ethylenic group confers biological activity to these compounds. These $\alpha, \beta$ - unsaturated ketones known as chalcones and also their derivatives are found to possess a wide spectrum biological and multiprotecting biochemical activities as well as number of commercial and industrial applications as reported ${ }^{1-13}$ with references there in. Literature survey shows many patents describing the usefulness of chalcones and their derivatives. Chalcones and their derivatives find varied applications as reported earlier ${ }^{11-13}$. Ortho-hydroxychalcones have good chelating properties and were exploited 
as analytical reagents for estimation of different metal ions ${ }^{14} .2$ '-hydroxylchalcones and their heterocyclic and naphthalene analogues are also reported to form coordination complexes ${ }^{14-26}$. Ruthenium complexes of 2'-hydroxychalcones ${ }^{27-34}$, chalcone oximes ${ }^{35}$ and chalcone semicarbazones $^{36,37}$ are synthesized and characterized by analytical and spectroscopic methods. The synthesis and bilological study of some new chalcones and pyrazole derivatives are also reported ${ }^{38}$. Synthesis and antimicrobial activities of $\mathrm{Co}(\mathrm{II}), \mathrm{Ni}(\mathrm{II})$ and $\mathrm{Cu}(\mathrm{II})$ complexes of some 2'-hydroxychalcones are also reported ${ }^{39}$. Synthesis and in vitro antiplaque activity of chalcone, flavonol and flavonol derivatives are also carried out ${ }^{40}$. The quantitative structure-activity relationships of mosquito larvicidal activities of a series of chalcones and some derivatives are also reported ${ }^{41}$. Some researchers ${ }^{16,23,26.39,42-44}$ have carried out thermal studies of chalcones as a part of their various studies.

M A Rahman ${ }^{45}$ in his review with the references there in, has highlighted the latest synthesised chalcones and their derivatives possessing a wide range of pharmacological activities, such as antimalarial, anticancer, antiprotozoal(antileishmanial and antitrypanosomal), antiinflammatory, antibacterial, antifilarial, antifungal, antimicrobial, mosquito larvicidal $^{41}$, anticonvulsant and antioxidant activities. They also show ${ }^{45}$ inhibition of the enzymes, especially mammalian alpha-amylase, cyclooxygenase (COX) and monoamine oxidase (MAO) and antimitotic activity too. Because of this, chalcones and their derivatives have once again attracted the increasing focus of the scientists for exploring newer and newer potent pharmacological activities in them.

This year, we have reported ${ }^{46}$ the presence and the effect of resonance stabilized intramolecular hydrogen bonding resulting into conjugate chelation in these naphthyl chalcones under present consideration and on their complexation with transition metals, $\mathrm{Cu}(\mathrm{II}), \mathrm{Ni}(\mathrm{II})$ and $\mathrm{Co}(\mathrm{II})$ through their electronic and ${ }^{1} \mathrm{H}$ NMR spectroscopic investigations. The conjugate chelation considerably alters the spectroscopic properties of the compounds and plays a very prominent role in the coordination chemistry particularly in changing the spectroscopic properties. ${ }^{1} \mathrm{H}$ NMR spectroscopy is the most powerful tool to detect the intramolecular hydrogen bonding. Electronic spectra are useful in establishing the geometry of complexes and also to detect and confirm the intramolecular hydrogen bonding with its effect in altering the spectral properties in the ligands as well as on their complexation with metal ions. Spectroscopic studies including the IR spectroscopic studies are very useful tools for the above said investigations.

Recently, we have investigated ${ }^{47}$ the indepth thermal studies of the same metal complexes as under present study, through their TGA and DTA analysis. The thermal studies supports an octahedral configuration as established from their electronic spectra for all the diaquo $\mathrm{Ni}(\mathrm{II})$ and $\mathrm{Co}(\mathrm{II})$ complexes of the ligands $o$-AnichaH, $p$-AnichaH and PipchaH with two water molecules providing fifth and sixth coordination sites

As reported in the literature ${ }^{48}$, I have investigated in detail the physico-analytical and magnetic susceptibility measurement study of the same metal complexes as under present study. The magnetic susceptibility measurements of these transition metal complexes have been carried out at room temperature by Faraday method. The magnetic moments of some copper complexes under present study are also determined from their ESR spectra recorded under different experimental conditions. The proposed structures, square planar, octahedral and oligomeric, wherever applicable, of metal complexes under present study are represented and explained in detail. This encouraged me to carry out the present work in which an attempt has been made to study and confirm the effect of intramolecular hydrogen bonding as mentioned above 
in the coordination chemistry of the compounds under consideration through their explorative IR spectroscopic investigations which further confirms the observations and results as reported ${ }^{46,48}$.

\section{Experimental}

All reagents and chemicals used were of Analar grade. All solvents used were of standard and spectroscopic grade. The IR spectra of metal complexes and the constituent ligands were recorded in $\mathrm{KBr}$ pellets on a Nicolet, USA, FT-IR Spectrophotometer in the range 4000-400 $\mathrm{cm}^{-1}$.

\section{Synthesis of naphthalene analogues of 2'-hydroxychalcones (Ligands)}

The naphthalene analogues of 2'-hydrochalcones, 1-(1-hydroxy-2-naphthyl)-3-phenyl-prop2-en-1-one(BenchaH), 1-(1-hydroxy-2-naphthyl)-3-(2-methoxyphenyl)-prop-2-en-1-one( $o$ AnichaH), 1-(1-hydroxy-2-naphthyl)-3-(4-methoxyphenyl)-prop-2-en-1-one(p-AnichaH),1(1-hydroxy-2-naphthyl)-3-(3,4-methylenedioxy phenyl)-prop-2-en-1-one(PipchaH), 1-(1hydroxy-2-naphthyl)-3-(3,4-dimethoxy phenyl)-prop-2-en-1-one (VerchaH) were prepared by the procedure as reported ${ }^{11-13}$ with their general structure as shown below:

\begin{tabular}{|c|c|c|c|}
\hline S. No. & Ligand No. & Ligand designated as & $-\mathrm{R}$ \\
\hline 1 & L-1 & BenchaH & $-\mathrm{H}$ \\
\hline 2 & L-2 & $o$-AnichaH & $2-\mathrm{OCH}_{3}$ \\
\hline 3 & L-3 & $p$-AnichaH & $\begin{array}{c}4-\mathrm{OCH}_{3} \\
-\mathrm{O}\end{array}$ \\
\hline 4 & L-4 & PipchaH & $3,4-\searrow_{-\varnothing} \mathrm{CH}_{2}$ \\
\hline 5 & L-5 & VerchaH & $3,4-\left(-\mathrm{OCH}_{3}\right)_{2}$ \\
\hline
\end{tabular}

\section{Synthesis of metal complexes of naphthyl chalcones}

The metal complexes of these naphthyl chalcones, BenchaH, o-AnichaH, $p$-AnichaH, PipchaH and VerchaH were prepared as per the procedure reported in our earlier work ${ }^{11-13}$.

\section{Results and Discussion}

The FT-IR spectra of all ligands and their metal complexes have been recorded in $\mathrm{KBr}$ discs in the region $4000-400 \mathrm{~cm}^{-1}$. Some of the structurally important FT-IR bands observed in the constituent ligands and their metal complexes with their assignments are summarized in Tables 1 and 2 .

\section{IR spectra of the ligands}

The spectra are quite complex due to the presence of a large number of bands with varying intensities. Hence, assignment of all the bands without ambiguity is not possible. However, an attempt has been made to identify and assign some of the structurally important bands on the basis of the reported infrared spectra of some chalcones ${ }^{15-17,23,26,49-56}$. Some of these like $v \mathrm{CH}($ Aromatic), $v \mathrm{C}=\mathrm{O}, v \mathrm{Ph}-\mathrm{C}=\mathrm{C}, \mathrm{Ph}-\mathrm{C}-\mathrm{C}$ (in plane), $\delta \mathrm{OH}$ (Phenol) and $v \mathrm{C}-\mathrm{O}$ (Phenol) are in good agreement with the reported values ${ }^{16,17,26,55}$. 
Table 1. Some important IR Bands in the ligands, 1-(1-hydroxy-2-naphthyl)-3-(phenyl or substituted phenyl)prop-2-en-1-ones and their assignments

\begin{tabular}{cccccccc}
\hline $\begin{array}{c}\text { S. } \\
\text { No. }\end{array}$ & Compound & $\begin{array}{c}v \mathrm{CH} \\
(\text { Aromatic) } \\
\mathrm{cm}^{-1}\end{array}$ & $\begin{array}{c}v \mathrm{C}=\mathrm{O} \\
\mathrm{cm}^{-1}\end{array}$ & $\begin{array}{c}v \mathrm{Ph}- \\
\mathrm{C}=\mathrm{C} \\
\mathrm{cm}^{-1}\end{array}$ & $\begin{array}{c}\text { Ph-C-C } \\
\text { (in plane) } \\
\mathrm{cm}^{-1}\end{array}$ & $\begin{array}{c}\delta \mathrm{OH} \\
(\mathrm{phenol}) \\
\mathrm{cm}^{-1}\end{array}$ & $\begin{array}{c}v \mathrm{C}-\mathrm{O} \\
(\mathrm{phenol}) \\
\mathrm{cm}^{-1}\end{array}$ \\
\hline 1 & BenchaH & 3050 & $\begin{array}{c}1628 \\
(1625)^{*}\end{array}$ & $\begin{array}{c}1574 \\
(1572)^{*}\end{array}$ & 1467 & 1351 & 1281 \\
2 & $o-$ AnichaH & 3060 & $\begin{array}{c}1632 \\
1579\end{array}$ & 1470 & 1357 & 1283 \\
3 & $p$-AnichaH & $\sim 3050$ & $\begin{array}{c}1632 \\
(1620)^{*}\end{array}$ & $\begin{array}{c}1566 \\
(1550)^{*}\end{array}$ & 1470 & 1357 & 1289 \\
4 & PipchaH & 3050 & 1629 & 1576 & 1488 & 1340 & 1308 \\
5 & VerchaH & $\sim 3040$ & 1638 & 1573 & 1470 & 1340 & 1308 \\
\hline \multicolumn{5}{c}{${ }^{*}$ Literature values $^{26}$} \\
\end{tabular}

Table 2. Some important IR bands in the metal complexes of 1-(1-hydroxy-2-naphthyl)-3(phenyl or substituted phenyl) prop-2-en-1-ones and their assignments

\begin{tabular}{|c|c|c|c|c|c|c|c|}
\hline $\begin{array}{l}\text { S. } \\
\text { No }\end{array}$ & Compound & $\begin{array}{c}v \mathrm{CH} \\
\text { (Aromatic) } \\
\mathrm{cm}^{-1}\end{array}$ & $\begin{array}{c}v \mathrm{C}=\mathrm{O} \\
\mathrm{cm}^{-1}\end{array}$ & $\begin{array}{l}\nu \mathrm{Ph}- \\
\mathrm{C}=\mathrm{C} \\
\mathrm{cm}^{-1}\end{array}$ & $\begin{array}{c}\mathrm{Ph}-\mathrm{C}-\mathrm{C} \\
\text { (in plane) } \\
\mathrm{cm}^{-1}\end{array}$ & $\begin{array}{c}\mathrm{vC}-\mathrm{O} \\
\text { (phenol) } \\
\mathrm{cm}^{-1}\end{array}$ & $\begin{array}{c}v \mathrm{M}-\mathrm{O} \\
\mathrm{cm}^{-1}\end{array}$ \\
\hline 1 & $\mathrm{Cu}(\text { Bencha })_{2}$ & $\sim 3065$ & $\begin{array}{c}1610 \\
(1610)^{*}\end{array}$ & $\begin{array}{c}1557 \\
(1550)^{*}\end{array}$ & 1479 & 1320 & $\begin{array}{c}614 \\
(612)^{*}\end{array}$ \\
\hline 2 & $\mathrm{Ni}(\text { Bencha })_{2}$ & 3060 & $\begin{array}{c}1615 \\
(1605)^{*}\end{array}$ & $\begin{array}{c}1562 \\
(1565)^{*}\end{array}$ & 1464 & 1317 & $\begin{array}{c}574 \\
(573)^{*}\end{array}$ \\
\hline 3 & $\mathrm{Co}(\text { Bencha })_{2}$ & 3080 & $\begin{array}{c}1610 \\
(1612)^{*}\end{array}$ & $\begin{array}{c}1568 \\
(1562)^{*}\end{array}$ & 1489 & 1300 & $\begin{array}{c}575 \\
(577)^{*}\end{array}$ \\
\hline 4 & $\mathrm{Cu}(o-\text { Anicha })_{2}$ & 3060 & 1610 & 1553 & 1468 & 1314 & 607 \\
\hline 5 & $\mathrm{Ni}(o \text {-Anicha })_{2} \cdot 2 \mathrm{H}_{2} \mathrm{O}$ & 3060 & 1620 & 1567 & 1489 & 1313 & 596 \\
\hline 6 & $\mathrm{Co}(o \text {-Anicha })_{2} \cdot 2 \mathrm{H}_{2} \mathrm{O}$ & 3050 & 1614 & 1561 & 1485 & 1310 & 590 \\
\hline 7 & $\mathrm{Cu}(p \text {-Anicha })_{2}$ & 3050 & $\begin{array}{c}1603 \\
(1590)^{*}\end{array}$ & $\begin{array}{c}1550 \\
(1540)^{*}\end{array}$ & 1478 & 1320 & $\begin{array}{c}593 \\
(590)^{*}\end{array}$ \\
\hline 8 & $\mathrm{Ni}(p \text {-Anicha })_{2} \cdot 2 \mathrm{H}_{2} \mathrm{O}$ & 3060 & $\begin{array}{c}1607 \\
(1595)^{*}\end{array}$ & $\begin{array}{c}1557 \\
(1555)^{*}\end{array}$ & 1485 & 1314 & $\begin{array}{c}576 \\
(570)^{*}\end{array}$ \\
\hline 9 & $\mathrm{Co}(p \text {-Anicha })_{2} \cdot 2 \mathrm{H}_{2} \mathrm{O}$ & $\sim 3060$ & $\begin{array}{c}1604 \\
(1600)^{*}\end{array}$ & $\begin{array}{c}1561 \\
(1555)^{*}\end{array}$ & 1460 & 1309 & $\begin{array}{c}572 \\
(568)^{*}\end{array}$ \\
\hline 10 & $\mathrm{Cu}$ (Pipcha) $)_{2}$ & 3060 & 1604 & 1555 & 1472 & 1320 & 616 \\
\hline 11 & $\mathrm{Ni}$ (Pipcha) $)_{2} \cdot 2 \mathrm{H}_{2} \mathrm{O}$ & 3060 & 1608 & 1563 & 1488 & 1316 & 617 \\
\hline 12 & $\mathrm{Cu}$ (Pipcha) $)_{2} \cdot 2 \mathrm{H}_{2} \mathrm{O}$ & 3050 & 1608 & 1568 & 1489 & 1315 & 618 \\
\hline 13 & $\mathrm{Cu}(\text { Vercha })_{2}$ & $\sim 3045$ & 1613 & 1553 & 1472 & 1319 & 620 \\
\hline
\end{tabular}

The broad bands in the $3060-3040 \mathrm{~cm}^{-1}$ region for all the ligands have been ascribed to $v \mathrm{CH}$ (Aromatic) vibrations ${ }^{55}$ and they are not substituent dependent. Chalcones and their naphthalene analogues like the ones under present considerations are $\alpha, \beta$ unsaturated ketones containing two aromatic rings which are interconnected by highly electrophilic three carbons, $\mathrm{CH}=\mathrm{CH}-\mathrm{C}=\mathrm{O}$ system that assumes linear or nearly planar structure. The chalcones possess conjugated double bonds and a completely delocalized $\pi$ electron system on both the rings.

As reported ${ }^{45}$ in the review, the chalcones have crystal structure. The molecule forms a zigzag chain by $\mathrm{C}-\mathrm{H}----\pi$ (arene) hydrogen bonds along the $\mathrm{c}$ axis. There also exists 
intermolecular hydrogen bonding interactions involving $\mathrm{C} 11$ acting as $\mathrm{H}$-bond donor, via $\mathrm{H} 11$, to $\mathrm{O}$ in the adjacent molecules at $-\mathrm{X}, 1-\mathrm{Y}, 1-\mathrm{Z}$, resulting in a three dimensional network.

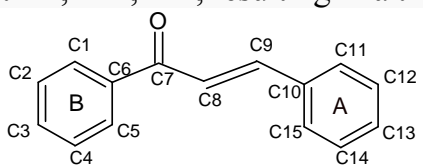

Chalcone (Parent)

But in the presence of strong resonance stabilized intramolecular hydrogen bonding in the present chalcones, the possibility of this type of intermolecular hydrogen bonding may be ruled out.

As reported earlier ${ }^{46}$, NMR studies clearly indicate that in $o$-hydroxychalcones, there exists an intramolecular hydrogen bonding between the 2'-hydroxy group and keto group. The keto-ethylenic group or enone function is in conjugation with phenyl or substuited phenyl group on one side and hydroxy naphthyl group on the other side. Such resonance stabilized hydrogen bonding also referred to as the conjugate chelation is responsible for the increased photostability of the molecule. The chelation in the six-membered ring ketones as like the present ones have been found to be much stronger than in the five membered ring. This hydrogen bond is the strongest as the hydrogen bonded structure is stabilized by the resonance.<smiles>[R]c1cccc(/C=C/C(=O)c2ccc3ccccc3c2O[Na])c1</smiles>

Structure (I)<smiles>[R]Oc1c(C(=O)/C=C/c2ccc([R])cc2)ccc2ccccc12</smiles>

Structure (II)

Where, $\mathrm{M}=\mathrm{Cu}(\mathrm{II}), \mathrm{Ni}(\mathrm{II}) \mathrm{Co}(\mathrm{II})$

IR spectra of the metal chelates are compatible with the structure that would result if the chelated hydrogen of the ligand as shown in the structure (I), is replaced by metal ion as in structure (II), without much structural alteration of the ligand during complexation, suggesting that in general the $\sigma-$ and $\pi$-electron system of the ligands did not undergo much considerable alteration on coordination to the metal ion. This accounts for the spectra of the metal chelates bearing close resemblances to those of the ligands. This is further confirmed by the fact that in the present study as indicated later, the IR spectra of the complexes suggest that carbonyl group is perturbed only slightly by coordination to the metal ${ }^{43}$.

As reported earlier ${ }^{48}$, the ligands in the present study can form $\beta$-ketoenolate anion like $\beta$-diketones such as acetylacetonate, due to tautomerisation and ionization. As stated earlier ${ }^{48}$, the presence of bulky substituents on the $\beta$-diketonates sterically impedes oligomerisation. But, due to the dispersal of negative charge on the two oxygen atoms and also on the carbon atoms of the ring of the anion of BenchaH i.e. Bencha', very large number of resonance structures are possible leading a very high resonance stabilization of this $\beta$-ketoenolate anion under consideration and perhaps this may be even far more than the resonance stabilization in acetylacetonate ion. This very high resonance stabilization may outweigh steric hindrance effect, if any, and makes the anion highly stable and this makes the proposed trimeric and tetrameric structures(X) and (XI) respectively highly stable.

The chelating ligands such as acetylacetonate enjoy resonance stabilization as a result of forming six membered rings having some aromatic character which stabilizes the chelate ring making it even more stable and this holds true even for the ligands with chelate ring 
under present consideration as explained subsequently. Chelate effect in conjunction with ability of the ligands to act as $\pi$ - acceptors as well as $\sigma$-donors further enhances the stability. Ligand-metal $\pi$ bonding further enhances delocalization of electrons as compared to that of the free ligand, producing some resonance stabilization.

Chelate ligands form more stable complexes than analogous monodentate ligands. Unsaturated ligands with a system of double and single bonds form very stable metal complexes containing six membered rings which include the metal ion also. This is because in such complexes the electron density is delocalized and spread over the ring which is thus stabilized by resonance. Such complexes containing chelating ligands with delocalized electronic structures are stabilized by electronic effect in addition to favourable entropy change during the chelation process.

Steric factor plays a significant roll in chelation. This arises due to the presence of a bulky group either attached to or near to a donor atom to cause mutual repulsion between the ligands thereby weakening the metal-ligand bond and this leads to lesser stability which is not so in present ligands. The chelate rings obey more or less the same type of steric requirements with respect to confirmations as do organic rings. Unlike organic ring system, maximum stability in chelate rings usually arises from five membered rings because the metal atom is larger than a carbon atom and the bond angles at the metal (L- M -L) will be $90^{\circ}$ in square planar and octahedral complexes in contrast to an optimum angle of $109.5^{0}$ for tetrahedral carbon. But for ligands like the present naphthyl chalcones under present consideration and acetylacetonates which exhibit resonance effects, six membered rings are highly stable.

Hydrogen bonding occurs between a proton donor group, X-H (hydroxyl, amine or amide groups) and a proton acceptor, y (oxygen, nitrogen and halogen atoms). Hydrogen bonds are the strongest when the hydrogen bonded structure is stabilized by resonance. Hydrogen bonding alters the force constant of both donor and acceptor groups. The frequencies of the stretching and bending vibrations are altered. The X-H stretching band moves to lower frequencies usually with increased intensity and band broadening. The stretching frequency of the acceptor group like $>\mathrm{C}=\mathrm{O}$ is also reduced, but it is to a lesser extent than that for $\mathrm{X}-\mathrm{H}$, the proton donor group. Depending on the strength of the bond, the shift in the $\mathrm{C}=\mathrm{O}$ stretching frequency may vary from 15 to $50 \mathrm{~cm}^{-1}$ and above, while the shift in the X-H stretching frequency may vary from 100 to over $500 \mathrm{~cm}^{-1}$. Intramolecular hydrogen bonding decreases the carbonyl frequency to a greater extent than the intermolecular hydrogen bonding. But on the other hand, the X-H bending vibration generally shows a small shift to higher frequency on hydrogen bond formation. The strength of the hydrogen bond is measured in terms of the difference in frequency between free $\mathrm{OH}$ and hydrogen bonded $\mathrm{OH}$ absorptions. The strength of the hydrogen bond is also determined by the molecular geometry and the nature of the proton donor and acceptor groups. The O-H stretching vibration of alcohols and phenols (like the present hydroxy naphthyl chalcones) are sensitive to hydrogen bonding.

In $o$-hydroxyacetophenone, strong intramolecular hydrogen bonding occurs and the absorption due to hydrogen bonded $\mathrm{O}-\mathrm{H}$ appears at $3077 \mathrm{~cm}^{-1}$ as a broad and weak band. On the other hand, it structural isomer, $p$-hydroxyacetophenone shows a sharp peak at $3600 \mathrm{~cm}^{-1}$ in dilute $\mathrm{CCI}_{4}$ due to free hydroxy group.

The resonance effect is observed in adjacent group containg $\pi$ electrons. For example, the $\mathrm{C}=\mathrm{O}$ stretching vibrations in a ketone and the $\mathrm{C}=\mathrm{C}$ stretching mode in ethene derivatives are usually near 1725 and $1650 \mathrm{~cm}^{-1}$ respectively. However in conjugated system 
$>\mathrm{C}=\mathrm{C}-\mathrm{C}=\mathrm{O}$, their frequencies are shifted to lower frequencies (higher wavelength) to 1693 and $1641 \mathrm{~cm}^{-1}$ respectively for $\mathrm{C}=\mathrm{O}$ and $\mathrm{C}=\mathrm{C}$. The conjugation of $\mathrm{C}=\mathrm{O}$ group with a $\mathrm{C}=\mathrm{C}$ group results in delocalization of $\pi$ electrons of both the unsaturated groups. Because of this there is an increase in double bond character of the $\mathrm{C}-\mathrm{C}$ linkage connecting two doubly bonded groups and a decrease in the double bond character of both the $\mathrm{C}=\mathrm{O}$ and $\mathrm{C}=\mathrm{C}$ groups. This is as a result of the fact that the $\pi$ electrons of the conjugated groups tend to delocalize over the entire molecule. The magnitude of the effect depends on the type of conjugation and on the specific compounds. For example, the conjugation of a $\mathrm{C}=\mathrm{O}$ group with an alkene or phenyl group causes absorption in the 1665$1685 \mathrm{~cm}^{-1}$ region as in acetophenone where the frequency appears at 1685 to $1687 \mathrm{~cm}^{-1}$.

Thus in infrared spectroscopy ${ }^{52-54}$, conjugation of ethylenic double bonds, or a carbonyl group and double bonds causes a shift from normal position to a longer wavelength. The unconjugated carbonyl group in acetone shows a band at $1718 \mathrm{~cm}^{-1}$, while conjugation with one phenyl group, as in acetophenone as stated above lowers the frequency to $1685-1687 \mathrm{~cm}^{-1}$ and conjugation with two phenyl groups, as in benzophenone further lowers the frequency to $1655 \mathrm{~cm}^{-1}$. Whether this shift due to mesomerism or to an actual lengthening of the bonds is not known. It is indicated that whenever, there is an increased opportunity for the contribution of the ionic resonance structure A, to the carbonyl group, B, a shift to higher wavelength or lower frequencies is observed.

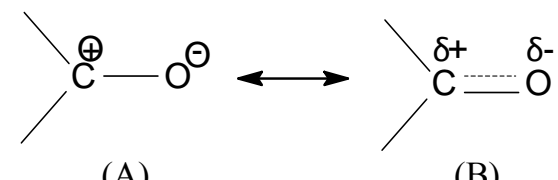

(A)

(B)

As expected from the participation of $\mathrm{A}$, the shifted band also has greater intensity.

Unsubstituted parent chalcone i.e. benzylidene acetophenone with structure shown earlier, shows a carbonyl band at $1659 \mathrm{~cm}^{-1}$, which is due to the conjugation with phenyl groups and an aliphatic double bond. Introduction of a hydroxyl group in 2' or 2- position is expected to shift the carbonyl band to higher wavelength or lower frequency ${ }^{52,54}$. Accordingly, both the 2'-hydroxychalcone and 2-hydroxychalcone shows ${ }^{52,54}$ the carbonyl band at $1639 \mathrm{~cm}^{-1}$. But, 2' -acetoxychalcone exhibits its carbonyl band $\mathrm{d}^{52}$ at around $1663 \mathrm{~cm}^{-1}$. Therefore, as expected acetylation was found to cause the absorption band to return to the original position. All these observations are explained as follows.It must be recalled that actophenone the carbonyl band is observed at 1685 to $1687 \mathrm{~cm}^{-1}$. But, when a hydroxyl group is introduced at ortho-position to the keto group in acetophenone, the carbonyl frequency is shifted from $1685-1687 \mathrm{~cm}^{-1}$ to $1635 \mathrm{~cm}^{-1}$, this effect of hydroxyl group, ortho to keto group in $o$-hydroxyacetophenone was first noted by Gordy ${ }^{57}$ who attributed it to hydrogen bonding between the hydroxyl group and keto group. Rasmussen et al. ${ }^{58}$ reinterpreted this shift as due to a conjugate-chelate system and also suggested that such a system is necessary for the occurrence of extreme shifts. Careful examination of the spectrum of $o$-hydroxyacetophenone indicates the absence of any band characteristic of free hydroxyl group. Similar behaviour was previously noted in the o-hydroxyanthraquinones ${ }^{59}$ and it was attributed to intramolecular hydrogen bonding. However, in 2-acetoxyacetophenone, the acylated product of $o$-hydroxyacetophenone, the carbonyl band is shifted back to higher frequency.

All these three facts seem to indicate further that conjugate chelation is responsible for the shift to the shorter frequency. However, $o$-methoxyacetophenone, where clearly 
neither hydrogen bonding nor conjugated chelation is possible, shows a band at $1649 \mathrm{~cm}^{-1}$. It seems likely therefore that this shift to longer wavelength or lower frequencies is due to participation of the resonance forms such as (III) in hydroxy derivative and (IV) in the case of the methoxyl derivative.

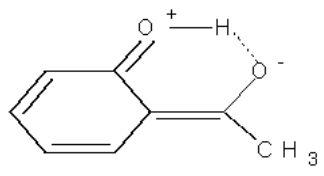

Structure (III)

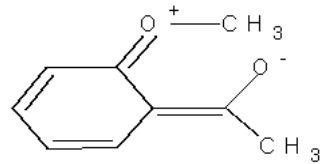

Structure (IV)

The increased stabilization in structure (I), due to the chelate ring plus presumably the greater ability of the hydroxyl group to donate electrons to the ring is responsible for the absorption in the high wavelength or the lower frequency in (III) than (IV). The tendency of the acetoxy group to donate electrons is very meager and this accounts for the acetoxy derivative not markedly differing from unsubstituted acetophenone.

It is a general observation that a chelated hydroxyl group ${ }^{58}$ does not show any absorption at $3600 \mathrm{~cm}^{-1}$; the band shifts to lower frequency regions and generally broad, probably due to the close vibrational levels ${ }^{60}$. Hydrogen bonding in enols and chelates is particularly strong. Literature survey reveals that very broad band may appear in regions as low as $2500 \mathrm{~cm}^{-1}$ in chelated compounds. Hydrogen bonding usually seems to broaden the band sometimes so broad as to be overlooked and shift if to lower frequencies. The stronger the hydrogen bonding, the greater is the lowering of the fundamental $\mathrm{O}--\mathrm{H}$ vibration frequency. Hydrogen bonding involves the lengthening of the original $-\mathrm{O}-\mathrm{H}$ bond which therefore gets weakened i.e. its force constant is reduced and therefore the stretching frequency is reduced. As stated earlier, the hydrogen bonding is also indicated by marked increase in the intensity of the absorption, longest shifts are observed, when the hydrogen bonding involves - $\mathrm{O}-\mathrm{H}$ groups and the least when it involves $-\mathrm{N}-\mathrm{H}$ group. There are also reports about broadening and large shifting of hydroxyl bands to the extent of disappearance. This is illustrated by the example of 1, 4-dihydroxyanthraquinone and 2,2'-dihydroxyazobenzene in which the hydroxyl absorpotion is so much shifted and broadened that when these compounds are examined under normal conditions, no band is detectable. It has also been observed that $-\mathrm{O}-\mathrm{H}$ absorptions are shifted to such an extent as stated earlier, that they overlap and obscure the absorption due to $-\mathrm{C}-\mathrm{H}$ regions and this makes the measurement almost impossible. Accordingly, it is observed ${ }^{52}$ that 2 'hydroxychalcone does not show the characteristic hydroxyl band.

As discussed earlier, it must be restated that intramolecular hydrogen bonding between carbonyl and hydroxyl groups shows lowering in carbonyl frequency ${ }^{53,61}$. The values obtained by the earlier researchers ${ }^{26}$ for some of the bands observed in the ligands BenchaH and p-AnichaH and their complexes are also given in Tables 1 and 2. As stated earlier, in 2 '- hydroxychalcone, the carbonyl bands occurs at $1639 \mathrm{~cm}^{-1}$. Natarjan et al. ${ }^{16}$ reported $v \mathrm{C}=\mathrm{O}$ band at $1622 \mathrm{~cm}^{-1}$ in 1-(2-hydroxy-1-naphthyl)-3-phenyl-2-propen-1-one. Natarjan and Tharmaraj ${ }^{26}$ reported $\mathrm{vC}=\mathrm{O}$ at $1625 \mathrm{~cm}^{-1}$ in 1-(1-hydroxy-2-naphthyl)-3-phenyl-2propen-1-one and this band in the same compound is observed in the present study at 1628 $\mathrm{cm}^{-1}$. Thus, from 2'- hydroxychalcone (the parent hydroxylchalcone) to the corresponding isomeric naphthalene analogues i.e. the parent isomeric hydroxynaphthyl chalcones, the replacement of the hydroxy phenyl ring by the hydroxyl naphthyl ring further shifts the carbonyl band from 1639 to $1628-1622 \mathrm{~cm}^{-1}$ and this further lowering in frequency may attributed to the extended conjugation ${ }^{52,53}$. 
In the light of above discussion, it is clear that the intense bands observed in the range of $1638-1628 \mathrm{~cm}^{-1}$, in the FTIR spectra of the ligands, the hydroxy naphthyl chalcones, whose metal complexes are under present study, is attributed to $\mathrm{vC}=\mathrm{O}$. In the present ligands, the frequency $\vee \mathrm{C}=\mathrm{O}$ is found to be the substituent dependent and follows the order:

\section{VerchaH $>$ o-AnichaH $=$ p-AnichaH $>$ PipchaH $>$ BenchaH}

In all the ligands, the $v \mathrm{C}=\mathrm{C}$ could not be identified because of its possible merger ${ }^{17,62}$ with $v \mathrm{C}=\mathrm{O}$.

The medium to high intensity bands appearing in the $1579-1566 \mathrm{~cm}^{-1}$ region for all the ligands are assigned to the $v \mathrm{Ph}-\mathrm{C}=\mathrm{C}$ vibrations ${ }^{15,17,23,26,49,55,56}$. The bands appearing in the $1488-1467 \mathrm{~cm}^{-1}$ region in all the ligands are ascribed to the $\mathrm{Ph}-\mathrm{C}-\mathrm{C}\left(\right.$ in plane) vibrations ${ }^{17}$.

The strong absorption bands were observed for the ${ }^{\delta} \mathrm{OH}$ (phenol) vibrations ${ }^{23,49,55}$ in the range $1357-1340 \mathrm{~cm}^{-1}$ region for all the ligands. The intense bands in the $1308-1281 \mathrm{~cm}^{-1}$ region for all the ligands have been attributed to the $\mathrm{vC}-\mathrm{O}$ (phenol) vibrations ${ }^{16,23,55,56}$.

\section{IR spectra of the metal complexes}

The infrared spectra of transition metal complexes are quite complex as they in general contain numerous bands of varying intensities. Hence, it is not possible to assign all the bands. However, some structurally important bands have been identified to draw inferences about the nature of bonding in these complexes.

The $v \mathrm{C}=\mathrm{O}$ bands in the FT-IR spectra of the metal complexes occur in the $1620-1603 \mathrm{~cm}^{-1}$ region. As stated earlier, this band occurs in the ligands in the $1638-1628 \mathrm{~cm}^{-1}$ region. Thus, this band is shifted to lower frequencies ${ }^{15-17,23,26,49,50,56}$ in metal complexes as compared to ligands. The shift towards lower frequencies is due to the coordination of the $>\mathrm{C}=\mathrm{O}$ group to the metal ion through oxygen resulting in decrease of bond order of carbon to oxygen linkage $\mathrm{e}^{15,23,49,56}$. With respect to the ligands, $\mathrm{vC}=\mathrm{O}$ of the metal complexes is lowered in general by $12 \mathrm{~cm}^{-1}$ [in the case of $\mathrm{Ni}(\mathrm{o}-\mathrm{Anicha})_{2} \cdot 2 \mathrm{H}_{2} \mathrm{O}$ ] to $29 \mathrm{~cm}^{-1}$ [in the case of $\mathrm{Cu}(\mathrm{p}$ Anicha $)_{2}$ ] indicating that coordination occurred via oxygen atom of the carbonyl oxygen group $^{43}$. And this decrease observed in these complexes is comparatively much smaller than that observed $\left(\Delta v=55-40 \mathrm{~cm}^{-1}\right)$ in the case of other metal complexes of chalcones and their heterocyclic analogues ${ }^{15}$. Stronger intramolecular hydrogen bonding in the ligands lead to a smaller decrease ${ }^{16}$ in the $v \mathrm{C}=\mathrm{O}$ frequency. The magnitude of decrease in $\mathrm{vC}=\mathrm{O}$ in these complexes would suggest both $\sigma$ and $\pi$ interaction of $\mathrm{C}=\mathrm{O}$ with the metal and this is explained in detail later. The intramolecular hydrogen bonding in the ligands under present study has been further confirmed from the electronic spectra and ${ }^{1} \mathrm{H}$ NMR spectra of the ligands and the electronic spectra of metal complexes as reported ${ }^{46}$.

As stated earlier, in relation to the ligands, $v \mathrm{C}=\mathrm{O}$ of the metal complexes under consideration is lowered by $12-29 \mathrm{~cm}^{-1}$, whereas the decrease observed in the case of $2^{\prime}-$ hydroxychalacones complexes ${ }^{17}$ is $1-7 \mathrm{~cm}^{-1}$ and this is explained as follows.

The magnitude of decrease in $\mathrm{vC}=\mathrm{O}$ in these complexes would suggest both $\sigma$ - and $\pi$ interactions with the metal (V) and (VI)
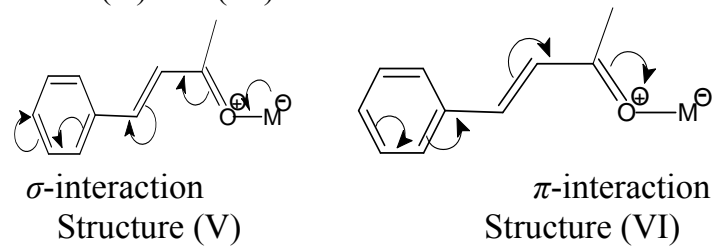
Due to the extended conjugation, a much lower $v \mathrm{C}=\mathrm{O}$ value in the metal complexes of 2'-hydroxychalcones than in $o$-hydroxyarylcarbonyl complexes and $o$-hydroxycrotonophenone complexes $^{63}$ is expected but indeed a relatively higher value is observed ${ }^{17}$. The $\pi^{*}$ orbital of the isolated $\mathrm{C}=\mathrm{O}$ group in $o$-hydroxyarylcarboyl complexes is localized more on carbon than on oxygen while, in chalcone complexes, the $\pi^{*}$ orbital of the conjugated system including the phenyl group will be found delocalized over the other carbon nuclei also ${ }^{64}$. As a result, $\mathrm{d}_{\pi}-\mathrm{p}_{\pi}$ back-bonding involving these orbitals would cause a very small change in $\mathrm{C}=\mathrm{O}$ bond order in the chalcone complexes and this is reflected in the very small decrease in $\mathrm{vC}=\mathrm{O}$ on coordination. The greater ligand field strength of $o$-hydroxycrotonophenone is due to a strong $\mathrm{d}_{\pi}-\pi^{*}{ }_{3}$ interaction which arises from the low energy of the $\pi^{*}{ }_{3}$ orbital (compared with $\pi^{*}$ of isolated $\mathrm{C}=\mathrm{O}$ ) of the conjugated system whereas in $2^{\prime}$-hydroxychalcones ${ }^{17}$, a further extension of conjugation is found to increase the ligand field strength. But, in the metal complexes under present study, the mesomeric interaction of the phenyl group with the metal is decreased due to the lack of the planarity of the naphthoyl moiety in the molecule. For effective delocalization of electron in a conjugated system, the molecule must be planar (or nearly so). Molecular model ${ }^{23}$ (VII) shows that $\mathrm{C}_{3}$-hydrogen of the naphthalene and $\alpha$-hydrogen of the styryl group are very close to each other, within the sum of their van der Waals radii, thus causing greater steric repulsion. This forces the styryl moiety of the complex out of plane with respect to the naphthoyl moiety ${ }^{16,26}$.

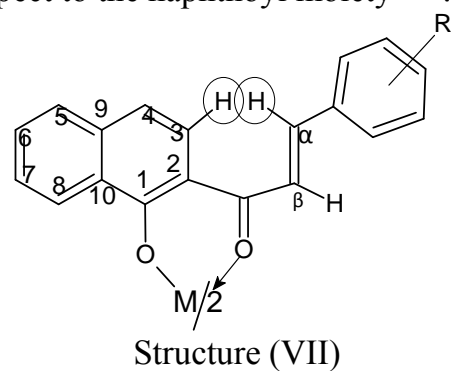

A comparative study of the electronic transmission effect of chalcone and $\beta$-naphthyl analogue of chalcone ${ }^{65}$ has shown that there is deviation from planarity in the latter, inhibiting conjugative interaction. Many ligands with more than one donor atom have geometries such that they can form more than one coordinate covalent bond to the same metal ion. Such ligands are known as potential chelating ligands which of course must be non linear and must form bond with reasonable angle(somewhere near $90^{\circ}$ or $109.5^{\circ}$ ) at the metal atom. By analogy with 2'-hydroxychalcones ${ }^{17}$, the ligands under present study are expected to be strong field ligand. But these ligands behave as weak field ligand because the energy of the of the $\pi^{*}{ }_{3}$ orbital of the conjugated system is not lowered sufficiently to cause strong $\mathrm{d} \pi-\pi_{3}{ }_{3}$ interaction due to the inhibition of the extensive conjugation arising from steric repulsion ${ }^{26}$ as discussed above.

The $v \mathrm{CH}$ (Aromatic) bands ${ }^{55}$ appearing in the $3060-3040 \mathrm{~cm}^{-1}$ region in the ligands are observed in the region $3080-3045 \mathrm{~cm}^{-1}$ region in the complexes.

The phenylalkene, ${ }^{v} \mathrm{Ph}-\mathrm{C}=\mathrm{C}$ vibrations observed in the $1579-1566 \mathrm{~cm}^{-1}$ region in the ligands is shifted to lower frequencies ${ }^{16,26,49}\left(\right.$ by $5-26 \mathrm{~cm}^{-1}$ ) in the metal complexes in which it is found in the $1568-1550 \mathrm{~cm}^{-1}$ region. The phenylalkene vibration is found to be metal sensitive and for the same phenyl substituent, it varies as $\mathrm{Co}>\mathrm{Ni}>\mathrm{Cu}$; this indicates relatively greater delocalization of electrons from highly populated d-orbitals of copper. This observed order is in total agreement with the order reported for metal complexes of other chalcones ${ }^{17,26}$. 
The Ph-C-C (in plane) vibration ${ }^{17}$ bands appearing in the ligands in the $1488-1467 \mathrm{~cm}^{-1}$ region are found to be at the $1489-1460 \mathrm{~cm}^{-1}$ in the complexes. From ligands to complexes, there are changes in these phenyl vibrations and roughly these vibrations may reflect the participation of the phenyl ring in mesomeric interaction with the metal.

The strong absorption bands observed for the $\delta \mathrm{OH}$ (phenol) vibration ${ }^{15,23,49,55}$ in the range 1357-1340 $\mathrm{cm}^{-1}$ region for all the ligands, were not observed in the complexes indicating the deprotonation of phenolic $-\mathrm{OH}$ of the ligand ${ }^{15,49}$.

The intense bands in the $1308-1281 \mathrm{~cm}^{-1}$ region for all the ligands, attributed to the $\mathrm{vC}-\mathrm{O}$ (Phenol) vibrations ${ }^{16,23,55,56}$ were observed in the $1320-1300 \mathrm{~cm}^{-1}$ region in the metal complexes. Thus, from the ligands to metal complexes, this band shifted positively $\left(7-39 \mathrm{~cm}^{-1}\right)$ upon coordination, a result which suggests that both carbonyl oxygen and phenolic oxygen are involved in coordination to the metal ${ }^{16,23}$.

\section{$M-O$ stretching vibration}

As expected, the IR spectra of the metal complexes show M-O stretching vibration as discussed below. Strong bands in the complexes in the region around $620-572 \mathrm{~cm}^{-1}$ are attributed to $v \mathrm{M}-\mathrm{O}$ vibrations and suggest bonding between metal ligand oxygen atoms ${ }^{15-17,26,49}$.

These bands are metal as well as phenyl substituent sensitive. For the same phenyl substituent, it follows the crystal field stabilization energy order, namely $\mathrm{Co}<\mathrm{Ni}<\mathrm{Cu}$, which indicates that it is determined by ligand field. This order is in accordance with Irving - Williams order of stabilities ${ }^{16,26}$. However, this order is equalized in the case of complexes of the ligand PipchaH and this deviation may be probably due to the presence of the additional heterocyclic ring in this ligand as compared to other ligands. But, as regards the effect of ligand substitution on $v \mathrm{M}-\mathrm{O}$, no regular sequence could be observed. It seems that electronic effects of the substituent are propogated to the chelate ring and that the resonance capacities of the substituents are important in determining $v \mathrm{M}-\mathrm{O}$.

The $v \mathrm{Cu}-\mathrm{O}$ bands are observed in the $620-593 \mathrm{~cm}^{-1}$ region, the $v \mathrm{Ni}-\mathrm{O}$ bands in the $617-$ $514 \mathrm{~cm}^{-1}$ region, whereas the $\mathrm{vCo}-\mathrm{O}$ bands are in the $618-572 \mathrm{~cm}^{-1}$ region. The small change in $v \mathrm{M}-\mathrm{O}$ (and $\mathrm{vC}=\mathrm{O}$ ) with change in the metal ions in the chalcone complexes can be attributed to the delocalization effects operating strongly in the conjugated system which minimize any vibration caused by changing the metal. This 'buffering action' is analogous to that of acetylacetonate complexes ${ }^{66}$.

As shown earlier, the mesomeric interaction of the phenyl group with metal ion in chalcone complexes can be represented by structures (V) and (VI). The effect of mesomeric electron release by the phenyl group is to increase the negative charge on the oxygen atom and cause a general strengthening of the M-O bonds. Superimposed on this effect, there would be an increased tendency towards $\pi$-bonding in the $\mathrm{M}-\mathrm{O}$ linkages. It can be seen that these effects would strengthen the $\mathrm{M}-\mathrm{O}$ and $\mathrm{C}-\mathrm{C}$ bonds more than the $\mathrm{C}=\mathrm{O}$ bonds of the chelate ring ${ }^{67}$. This would also lead to significant shifts in the phenyl vibrations. So, it is concluded that $\pi$-delocalization assumes great importance in deciding the nature of bonding, structure and stability of carbonyl complexes.

\section{Structures of metal complexes}

On the basis of magnetic, physical and analytical data, spectral and thermal properties ${ }^{46-48}$, it is found that all the copper(II) chelates are anhydrous monomers of trans-square-planar configuration, while the diaquo nickel(II) and cobalt(II) chelates have a high spin transoctahedral configuration $^{13}$ and may be represented by the structures (VIII) and (IX) respectively as shown below, which are already reported ${ }^{48}$. 
For Square - Planar Cu(II) Complexes<smiles>[R]c1ccc(/C=C/C2=C(/C=C/c3ccc([R])cc3)c3ccc4ccccc4c3O[C]2Oc2c(/C=C/c3ccccc3)ccc3ccccc23)cc1</smiles>

Structure (VIII)
For Diaquo Ni(II) and Co(II) Complexes

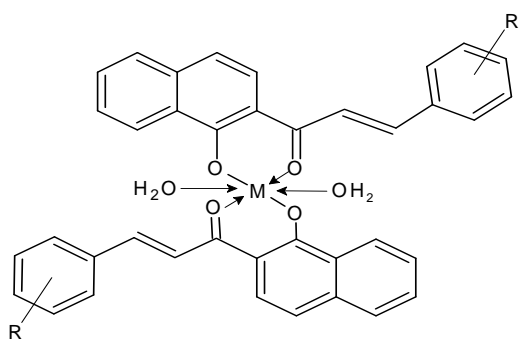

Structure (IX)

$$
\mathrm{M}=\mathrm{Ni}(\mathrm{II}) \text { and } \mathrm{Co}(\mathrm{II})
$$

The anhydrous $\mathrm{Ni}(\text { Bencha })_{2}$ and $\mathrm{Co}(\text { Bencha })_{2}$ complexes are polymers ${ }^{16,26,68}$, possibly a trimer $^{16,26,48,68}$ and a tetramer ${ }^{48,68}$ respectively with a high-spin trans-octahedral configuration which are comparable to the reported ${ }^{68}$ configurations for $\mathrm{Ni}(\mathrm{II})$ and $\mathrm{Co}(\mathrm{II})$ complexes of acetylacetonate with the same type of donor system as the present one. As a result of the sharing ${ }^{68}$ of some oxygen atoms, each metal atom achieves octahedral coordination. These two complexes may be represented by schematic structures (X) and (XI) respectively which are same as the structures reported ${ }^{68,69}$ for $\mathrm{Ni}(\mathrm{II})$ and $\mathrm{Co}(\mathrm{II})$ complexes of acetylacetonate. These structures (X) and (XI) are explained in detail in the earlier report ${ }^{48}$.

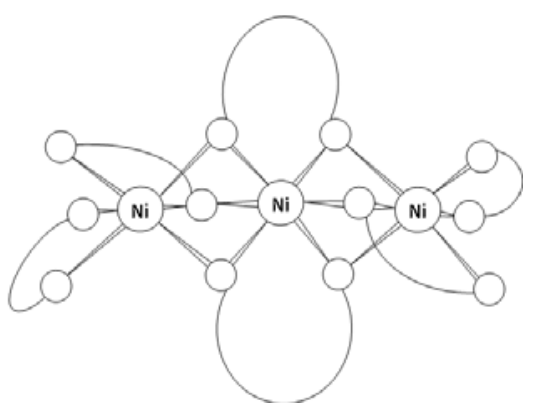

Structure $(\mathrm{X})$

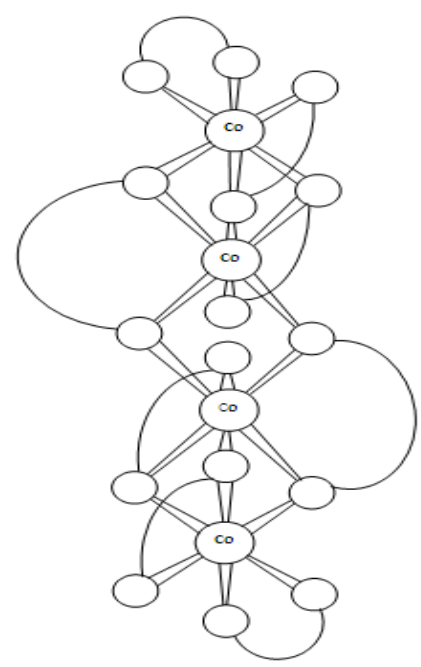

Structure(XI)

Schematic representation of trimeric Schematic representation of tetrameric structure of bis(Bencha) nickel(II). The structure of bis(Bencha) cobalt(II). The unlabeled circles represent $\mathrm{O}$ (oxygen) unlabeled circles represent $\mathrm{O}$ (oxygen) atoms atoms and the curved lines connecting them and the curved lines connecting them in pairs in pairs represent the remaining portions of represent the remaining portions of the anion the anion of the BenchaH rings of the BenchaH rings

\section{Conclusion}

The strong resonance stabilized intramolecular hydrogen bonding and also conjugated chelation considerably alters the IR spectroscopic properties of the compound and plays a 
very significant role in the coordination chemistry. IR spectroscopy as discussed is a very useful tool not only to detect the intramolecular hydrogen bonding but also its effects in the molecule and also the effects of conjugated chelation. It is also very useful in determining the geometries of the metal complexes. For the study of hydrogen bonding IR spectroscopy is the most sensitive and direct method.

\section{Acknowledgement}

The author, gratefully thanks, Late Dr. S.S. Dodwad for his valuable guidance. The author also thanks Principal and Head, Department of Chemistry, Mithibai College, Vile-Parle (West), Mumbai-400 056, India, for their valuable help and support.

\section{References}

1. Lee Y S, Lim S S, Shin K H, Kim Y S, Ohuchi K and Jung S H, Biol Pharm Bull., 2006, 29(5), 1028-1031; DOI:10.1248/bpb.29.1028

2. Ye C L, Liu J W, Wei D Z, Lu Y H and Qian F, Canc Chemo Pharm., 2005, 55(5), 447-452; DOI:10.1007/s00280-004-0917-8

3. Ye C L, Liu J W, Wei D Z, Lu Y H and Qian F, Pharmacol Res., 2004, 50(5), 505510; DOI:10.1016/j.phrs.2004.05.004

4. Sasayama T, Tanka K, Mizukawa K, Kawamura A, Kondoh T, Hosoda K and Kohmura E, J Neu Onc., 2007, 85(2), 123-132; DOI:10.1007/s11060-007-9395-2

5. Haraguchi H, Ishikawa H, Mizutani K, Tamura $\mathrm{Y}$ and Kinoshita T, Bioorg Med Chem., 1998, 6(3), 339-347; DOI:10.1016/S0968-0896(97)10034-7

6. Hsieh H K, Lee T H, Wang J P, Wang J J and Lin C N, Pharm Res., 1998, 15(1), 39-46; DOI:10.1023/A:1011940401754

7. Flechtner T W, Carbohyd Res., 1979, 77(1), 262-266; DOI:10.1016/S00086215(00)83816-1

8. Chang H J, Yoon G, Park J S, Kim M H, Baek M K, Kim N H, Shin B A, Ahn B W, Cheon S H and Jung Y D, Biol Pharm Bull., 2007, 30(12), 2290-2293; DOI: $10.1248 / \mathrm{bpb} .30 .2290$

9. Rauf S, Gooding J J, Akhtar K, Ghauri M A, Rahman M, Anwar M A and Khalid A M, J Pharm Biomed Anal., 2005, 37(2), 205-217; DOI:10.1016/j.jpba.2004.10.037

10. Pandey M K, Sandur S K, Sung B, Sethi G, Kunnumakkara A B and Aggarwal B B, J Biol Chem., 2007, 282(24), 17340-17350; DOI:10.1074/jbc.M700890200

11. Agharia E R and Dodwad S S, Asian J Chem., 1996, 8, 449-454.

12. Agharia and E R and Dodwad S S, Bull Pure Appl Sci., 1996, 15C, 1-7.

13. Agharia E R, Dodwad S S and Salvi S L, Oriental J Chem., 1996, 12, 251-256.

14. Ramakrishnaiah C H, Naidu R S and Naidu R R, J Indian Chem Soc., 1986, 63, 573.

15. Rao T S, Reddy K L, Swamy S J and Lingaiah P, Indian J Chem., 1985, 24A, 942.

16. Natarajan C, Shanthi P, Athappan P and Murugesan R, Trans Met Chem., 1992, 17(1), 39-45; DOI:10.1007/BF03325413

17. Palaniandavar M and Natarajan C, Aust J Chem., 1980, 33(4), 737-745; DOI:10.1071/CH9800737

18. Akuskar S K, Chondhekar T K and Dhuley D J, Asian J Chem., 1997, 9, 336-340.

19. Naidu R R and Naidu R S, Proc Indian Acad Sci., 1975, 82(4)A, 142-145.

20. Biradar N S, Patil B R and Kulkarni V H, Montash Chem., 1976, 107, 251.

21. Biradar N S, Patil B R and Kulkarni V H, Rev Roum Chim., 1977, 22, 1479.

22. Sumathi S, Tharmaraj P, Sheela C D and Ebenezer R, J Coord Chem., 2011, 64(10), 1707-1717; DOI:10.1080/00958972.2011.580844 
23. Naidu R S and Naidu R R, J Inorg Nucl Chem., 1979, 41(11), 1625-1627; DOI:10.1016/0022-1902(79)80194-3

24. Reddy V, Patil N and Patil B R, J Ind Council Chem., 2006, 23(2), 1-3.

25. Natrajan C and Palaniandavar M, J Chem Sci., 1983, 92(3), 265-270; DOI:10.1007/BF02841244

26. Natarajan C and Tharmaraj P, Trans Met Chem., 1987, 12(6), 553-557; DOI:10.1007/BF01023848

27. Dharmaraj N and Natrajan K, Ind J Chem., 1994, 33A, 785.

28. Kaveri M V, Prabharakan R, Karvembu R and Natrajan K, Spectrochim Acta, 2005, 61(13-14)A, 2915-2918; DOI:10.1016/j.saa.2004.11.001

29. Silva A M S, Cavalerio J A S, Tarragob G and Marzin C, New J Chem., 1999, 329336; DOI:10.1039/A809005J

30. Dharmaraj N and Natrajan K, Synth React Inorg Met Org Chem., 1997, 27(3), 361 375; DOI:10.1080/00945719708000194

31. Mishra L, Sinha R and Pandy P C, Metal Based Drugs, 2001, 2, 113.

32. Mishra L and Sinha R, Indian J Chem., 2000, 39A, 1131.

33. Novakova O, Kasparkova J, Vrana O, Vliet P M V, Reedijk J and Brabec V, Biochem., 1995, 34(38), 12369-12378; DOI:10.1021/bi00038a034

34. Mishra L, Sinha R, Itokawa H, Bastow K F, Tachibana Y, Nakanishi Y, Kilgore N and Lee K H, Bioorg Med Chem., 2001, 9(7), 1667-1671; DOI:10.1016/S09680896(01)00074-8

35. Sharma V K, Pandey O P andSengupta S K, Synth React Inorg Met Org Chem., 1991, 21(10), 1587-1599; DOI:10.1080/15533179108020630

36. Kowol C R, Eichinger R, Jakupee M A, Galanski M, Arion V B ad Keppler B K, $J$ Inorg Biochem., 2007, 101(11-12), 1946-1957; DOI:10.1016/j.jinorgbio.2007.07.026

37. Sharma V K, Pandey O P and Sengupta S K, Synth React Inorg Met Org Chem., 1991, 21(10), 793-806; DOI:10.1080/15533179108016843

38. Tala S D, Vekariya P B, Ghetiya R M, Dodiya B L and Joshi H S, Ind J Chem., 2013, 52B, 807-809.

39. Habib S I, Basseer M A and Kulkarni P A, Der Chemica Sinica., 2011, 2(1), 27-32.

40. Patil V C, Int J Pharm Sci Res., 2012, 3(12), 5006-5014.

41. Pasquale G, Romanelli G P, Juan C. Autino, Garcia J, Ortiz E V and Duchowicz P R, J Agric Food Chem., 2012, 60(2), 692-697; DOI:10.1021/jf203374r

42. Rao T S, Reddy K L and Lingaiah P, Proc Indian Acad Sci (Chem Sci)., 1988, 100, 363-373.

43. Khalil M M H, Ramadan R M, Salem M A I, Marzouk M I and Moftah M S, Egy J Pure Appl Sci., 2011, 19-29.

44. Patange V N and Arbad B R, J Serb Chem Soc., 2011, 76, 1237-1246.

45. Rahman M A, Chem Sci J, 2011, 29, 1-16.

46. Agharia E R, J Applicable Chem., 2014, 3(3), 1059-1072.

47. Agharia E R, Int Res J Chem., 2014, 5, 1-10.

48. Agharia E R, $J$ Applicable Chem., 2014, 3(6), 2514-2525

49. Venkatraman V R, Kather M S, Mansoor I and Nagarajan S, J Indian Chem Soc., 1986, 63, 925.

50. Satpathy K C, Panda A K, Mishra R, Chopdar A P and Pradhan S K, J Indian Chem Soc., 1994, 71, 593.

51. Trakroo P P and Mukhedkar A J, J Indian Chem Soc., 1964, 41, 595.

52. Sabata B K and RoutM K, J Indian Chem Soc., 1964, 41, 74. 
53. Hergert $\mathrm{H}$ Land Kurth E F, J Am Chem Soc., 1953, 75(7), 1622-1625; DOI:10.1021/ja01103a031

54. Nayak A, Nayak P L, Sabata B K and Rout M K, J Indian Chem Soc., 1964, 41, 507.

55. Dhar D N and Misra S S, J Ind Chem Soc., 1972, 49, 629.

56. Biradar N S, Patil B R and Kulkarni V H, Current Science, 1976, 45(6), 203.

57. Gordy W, J Chem Phys., 1940, 8, 516; DOI:10.1063/1.1750704

58. Rasmussen R S, Tunnicliff D and Brattain R, J Am Chem Soc., 1949, 71(3), 10681072; DOI:10.1021/ja01171a087

59. Flett M St C, J Chem Soc., 1948, 1441-1448; DOI:10.1039/JR9480001441

60. Pimental and McClellan, The Hydrogen Bond, 1960, P. 103, Freeman and Company, London.

61. Martin A E, Nature, 1950, 166(4220), 474; DOI:10.1038/166474a0

62. Bellamy L J, The Infrared Spectra of Complex Molecules, 1966, P. 89, Methuen, London.

63. Palaniandavar M and Natarajan C, Aust J Chem., 1980, 33(4), 729-736.

64. Hendrickson J B, Cram D J and Hammond G S, Organic Chemistry, 1970, P. 146, Kogakusha, Tokyo.

65. Rajasekaran K and Gnanasekaran C, Indian J Chem., 1986, 25A, 64.

66. Cotton F A, Modern Coordination Chemistry, (Eds., Lewis J and Wilkins R G), 1960, P. 382, Inter Science, New York.

67. Nakamoto K, Morimoto Y and Martell A E, J Phys Chem., 1962, 66, 346.

68. Cotton F A and Wilkison G, Advanced Inorganic Chemistry, 1976, $3^{\text {rd }}$ Ed., P.877, 878,898 and 899, Wiley Eastern Ltd., New Delhi.

69. Cotton F A, Wilkison G, Murillo $\mathrm{C}$ A and Bochmann M, Advanced Inorganic Chemistry, 2013, $6^{\text {th }}$ Ed., P.479, 480, 817 and 818, Wiley India Pvt. Ltd. 